\title{
PRE-SERVICE TEACHERS' CRITICAL REFLECTION ON THE KNOWLEDGE AND SKILLS LEARNED IN LIFE SCIENCES METHODOLOGY MODULE
}

\author{
Lydia Mavuru \\ Department of Science and Technology Education, University of Johannesburg (South Africa)
}

\begin{abstract}
The complex roles teacher educators and teachers face require their ability to critically reflect on their practices. The question is on whether teachers are trained to make critical reflections of learning experiences for them to be able to critically reflect on their teaching practices. Based on constructivist approach, teacher educators continuously reflect on their practices in order to modify and improve their modules. It is however imperative that pre-service teachers who are the recipients, be given an opportunity to critically reflect on the services they receive and at the same time develop critical reflection skills. By creating reflective teaching and learning environments in the Life Sciences Methodology and Practicum module at the beginning of the academic year, 77 Bachelor of Education students specialising in Life Sciences and in their last year of study at a South African University, were purposefully selected to participate in a qualitative study. The study sought to answer the research questions: 1. What are pre-service teachers' reflections on the knowledge and skills learned in their last year of study? and 2. What pedagogical and content knowledge aspects can be drawn from pre-service teachers' critical reflection for the improvement of the module Life Sciences Methodology and Practicum? In collecting data, each pre-service teacher was tasked to compile a critical reflection report which they submitted towards the end of the year, and was analysed through content analysis. The findings showed important knowledge and skills learned which included the contextualization of teaching to ensure learners comprehend abstract concepts such as immunity. Amongst the teaching approaches and strategies covered in the module, argumentation as a social constructivist strategy stood out particularly when teaching controversial topics embedded with socioscientific issues e.g. genetics and evolution. The pre-service teachers indicated that the way practical work was taught, equipped them with knowledge and skills on how inquiry-based approaches can be implemented in the classrooms. Suggestions to improve the module included the provision of pre-service teachers with opportunities to conduct virtual micro lessons in light of COVID-19 pandemic; that the testing of Life Sciences concepts should include the assessment of pre-service teachers' capabilities to teach the same concepts in the classrooms. The pre-service teachers' argument is that since they are in their final year, the focus of the module should be on the development and assessment of their pedagogical content knowledge (PCK) and TPACK. The findings of the study have implications for teacher professional development.
\end{abstract}

Keywords: Critical reflection, life sciences, knowledge and skills, pre-service teachers.

\section{Introduction}

As with most professional development programmes, critical reflection in teacher education plays an important role in improving the quality of teaching and learning (Šarić \& Šteh, 2017). The global trend in science education focuses on meaningful and authentic science teaching and learning, which can only be achieved if teachers are reflective practitioners. Despite the consensus role of reflection in teacher development, the actual reflection thereof remains minimal. Previous researchers (e.g. Moon, 2004; Van Eekelen, Vermunt, \& Boshuizen, 2006) have debated on teachers' readiness and capabilities to engage in reflection. Šarić and Šteh (2017) questioned whether teachers are developed with skills to critically reflect on teaching and learning practices during in-service teacher professional development. Emanating from the problem statement, the current study demonstrates how pre-service teachers were engaged in a practice of reflecting on their educators' practices and in the process inculcate in them a culture of critical reflection on own practice. The assumption is that as pre-service teachers were engaged in a critical reflection of what and how they were taught, this fostered intuitive knowledge and skills in reflecting on how they in turn could teach their own learners. Consequently, the study sought to answer the research questions: 1. What are pre-service teachers' reflections on the knowledge and skills learned in their last year of study? and 2. What pedagogical and content knowledge aspects can be drawn from pre-service teachers' critical reflection for the improvement of the module Life Sciences Methodology and Practicum? 


\section{Literature review}

Teacher educators are challenged to foster critical reflection in their modules and at the same time in modelling reflective practice for their pre-service teachers (Šarić \& Šteh, 2017). Critical reflection transforms teachers into flexible practitioners who are responsive to the diverse sociocultural and political contexts affecting the teaching and learning process (Zeichner, 2006). This is pertinent particularly in education systems that cater for learners who come from culturally, ethnically, and racially diverse contexts for example South Africa. There is a lack of clarity on the definition of critical reflection from literature but the current study takes the conceptualisation by Liu (2015) that critical reflection involves one to always analyse, question, and critique one's assumptions about teaching and learning and how the society and politics have implications on the implementation process. Liu (2015) proposed that teacher educators should go beyond the mere development of reflective teaching, but teach and foster critical reflection in pre-service teachers. In concurrence, Krumm and Kimmie (2013) pointed out that to improve learners' performance in science the teaching should be transformative where learners are empowered to take responsibility of their own learning process by interrogating and critically reflecting on their thought processes.

The current study is underpinned by the social constructivist theory since reflection is conceptualised as a communal process of teachers supporting each other to gain professional growth (Zeichner \& Liston, 1996). For effective reflection to occur, one has to be involved in interactive and collaborative learning (Maor, 2003), which is characteristic of social constructivist learning environments.

\section{Methodology}

This study adopted the qualitative interpretive paradigm and employed a qualitative case study design. The interpretive qualitative approach allowed the researcher to discern and understand the participants' reflections on the content they had learned in the module Methodology and Practicum for Life Sciences, a course that prepared them for classroom practices and experiences. Through a qualitative case study (Creswell, 2014), the participants' perceptions of the relevance of the knowledge and skills they learned could be deduced. At the beginning of the academic year, 77 Bachelor of Education students (referred in as pre-service teachers) specialising in Life Sciences and in their last year of study at a South African University, were purposefully selected as participants. In collecting data, each pre-service teacher was tasked to compile a report in which they reflected on the knowledge and skills learned in the Life Sciences Methodology module. The specifications of the reflection were that it should show evidence of the knowledge and skills acquired and their relevance, the adequacy or inadequacy of the development attained, and reflections on what went well and what could have been done differently in the implementation of the module. The reports were submitted towards the end of the year. Through content analysis the researcher carefully reviewed the reflections to identify pertinent information from nonpertinent information and to make sure the information was organised into categories related to the research questions (Bowen, 2009).

\section{Research findings}

The findings from the pre-service teachers' reflections raised important aspects on knowledge and skills acquired, and their relevance in preparing them for meaningful classroom practices when they qualify. The pre-service teachers raised important issues on the adequacy or inadequacy of the development attained. Of note are suggestions made on the aspects to be improved on the methodology course and its implementation in order to fully develop upcoming groups of pre-service Life Sciences teachers.

\subsection{Relevant knowledge learned in the methodology course}

The pre-service teachers were quite explicit on the knowledge and skills they learned in the module during the course of the year. It was evident that their reflections were measured against the content they had been exposed to in the previous three years and as well as the experiences they had when they taught in actual Life Sciences classrooms during school experience. They indicated that an analysis and interpretation of the Life Sciences curriculum at the beginning of the year was profound as it provided them with the baseline for their understanding of the content learned throughout the year. The participants appreciated the experiences as they reminisced that being a teacher is more than knowing and understanding the content, but it is also about knowing how to present the content you are teaching. Just to put the reader in context, these pre-service teachers had been taught Life Sciences in the Faculty of Science, and Life Sciences methodology course in the Faculty of Education. In this case, they were now connecting the relationship between the content they learned with the manner in which it should be taught to high school learners. It is unfortunate that for the previous three years, they were learning Life Sciences content and the pedagogical knowledge learned in the methodologies as discrete knowledge and skills. According to the participants, it was now in this module that the content and methodology were being 
merged to close the gap. To show their realisation and appreciation, one of the participants wrote, "The module provided me with pronounced knowledge to prepare me for the schools in my community".

The pre-service teachers pointed out that during the course of the module controversial topics e.g. evolution, genetics and reproduction, proved to be complex in nature and required sensitivity when teaching them and that the module developed them on how to approach these particular topics. In their reflections they acknowledged the importance of treating each topic in Life Sciences as unique and consider the different unique approaches of teaching them. Such knowledge was learned through contextualisation of the teaching and learning process, which they viewed as one of the themes which they valued in preparing them for real classroom diverse contexts. In this case, they indicated that knowledge and skills in the development of teaching strategies that take into consideration contextual factors helped them a lot. The following are some of the excerpts from the pre-service teachers' reflections. One of the participants wrote, "I learned some of the limitations, efficiencies and appropriateness of the teaching approaches and strategies for particular Life Sciences topics. The other had this to say:

Life Sciences is unique and has different unique ways of teaching it. I had done a task based on cloning and that assignment had given me a better understanding of being a teacher who knows how to handle different controversial topics and handling them with an understanding that learners may come from different racial/cultural and religious backgrounds and may seem to dislike/disregard certain concepts. As a teacher you must find ways to explain and teach the lesson in an unbiased manner and by maintaining a stable classroom environment.

From these reflections, it shows that the module equipped the pre-service teachers with relevant knowledge and skills to teach Life Sciences in different classroom contexts.

The pre-service teachers' engagement with the constructivist teaching philosophies and teaching strategies as applied in Life Sciences teaching helped them to appreciate the adaptation of teaching strategies for different contexts. They indicated that it helped them realise the need to understand the learners in a Life Sciences classroom in terms of their sociocultural backgrounds, their learning styles and preferences. In this way learners' prior knowledge should be elicited and teachers need to use examples familiar to learners and make references to their lived experiences in their different communities. As such one of the pre-service teachers wrote the following as extracted in the reflection report:

Engaging with constructivist philosophies and strategies provided me with the knowledge and skills of always using strategies that break down large chunks of Life Sciences content into digestible information for learners. It made me aware that not all learners grasp information in the same way and at the same pace. As such I now focus on diversifying my teaching strategies, examples and activities.

The pre-service teachers indicated that they realised that knowing the learners helps the teacher to prepare for meaningful teaching and learning.

The pre-service teachers commented on how they were fascinated by both the content and the manner in which the module was implemented which taught them to work under pressure and in unfamiliar situations particularly that at the beginning of the year they had face to face lectures and from March they transitioned rapidly to online lectures and assessments due to the COVID-19 pandemic. In this regard, they learned to embrace, adapt and accept changes encountered in the profession. To show the confidence the pre-service teachers acquired from the course, one of them said, "From everything that I have learned in this module I can confidently say that I am fulfilled, and I feel very much prepared for the world of work".

4.1.1. Important pedagogical practices and skills learned in the methodology. The pre-service teachers appreciated the opportunities they got in practising teaching different Life Sciences topics using the different approaches learned throughout the module. These activities included micro lessons where they developed interpersonal and presentation skills. They indicated that these soft skills developed as a result of the feedback from lecturers and colleagues who observed them teaching. Through encouragement and constructive criticism, they developed confidence as teachers and inculcated in them the skills of building confidence in their learners in their future Life Sciences classrooms. The following is an excerpt from one of the pre-service teachers.

As we had presentations earlier during the year I was able to observe how other student teachers teach and reflect on some of their teaching skills. This assisted me to identify things that should and should not be done.

Discussions during face to face and online lectures helped them on how they can initiate, manage and sustain discussions in their own classrooms. According to the pre-service teachers, if the lecturers could use discussions so effectively in the Life Sciences Methodology module, which had close to a hundred students, surely they could do the same in their overcrowded Life Sciences classrooms with around 50 learners. In South African classrooms, classroom management skills are pertinent considering that learner discipline is a big issue.

The pre-service teachers also reflected on the teaching approaches and strategies they learned and how important it was for them to observe each other employing such approaches when teaching 
micro lessons. The participants mentioned particularly the use of real-life case scenarios, inquiry-based approaches and argumentation as pertinent strategies that captivate learner interest to engage meaningfully in learning. They reflected on how the module also taught them the importance of practical and investigative work as effective science teaching approaches despite the 'lack of resources', which most teachers normally mourn about. The following is an excerpt from one of the reflection report.

The module broadened my understanding on what is practical work is examples of practical work, why do it, how to manage investigations, safety in the labs and also assessing for learning through practical work.

In their reflection reports, the participants indicated how much they have learned that as teachers it is important to get out of one's comfort zone and be innovative when teaching. They pointed out how much they were now wary about the various teaching strategies and their dynamics especially when they were contrasting the traditional methods which their high school teachers employed with the active learner-centred approaches they were taught in the Methodology and Practicum module. In summary the pre-service teachers reflected how much they have become critical thinkers. One of the participants wrote,

I can now dissect complex information through the controversial and philosophical discourses which come out as topics in Life Sciences such as evolution, genetics, human impact on the environment etc. are taught.

As such, the participants reflected on how their ICT knowledge and skills developed $\mathrm{i}$ as it was mandatory that they use technology when teaching. The pre-service teachers indicated that they were also equipped to develop 21 st century skills in their learners. They could now design and formulate online assessments through Google forms, Kahoot, using FlipGrid to engage learners and formulate quizzes through Mentimeter. They indicated that they learned about many other online resources that they could use in their own teaching. They also indicated that they acquired skills on how to design a fair and valid test which meets all levels of Bloom's taxonomy.

The pre-service teachers reflected on motivational and conflict resolution skills which were taught through the manner in which the lecturers behaved during lectures. In turn the pre-service teachers were equipped on how to also remain calm and professional even during the tough moments in the classrooms. These skills are very important particularly in today's overcrowded classrooms where classroom management skills are needed more than before. The pre-service teachers reflected on how the skills they learned such as empathising and building trust with learners, were important in contemporary classrooms where learners come from diverse backgrounds in terms of broken homes, poor socio-economic backgrounds and abused backgrounds. They realised that as teachers they needed to act in 'loco parentis'.

4.1.2. Aspects which could be done differently in future methodology classes. Whilst the pre-service teachers raved about the knowledge and skills they learned in the module, they also critically reflected on the negative things that they thought could have been done differently to improve their experiences. They felt strongly that the lecturers took for granted the issue of English language (medium of teaching and learning), which is a second and third language to most of the pre-service teachers from township backgrounds. They gave an example of how they wished they were given elaborate instructions on how to complete assessments. They bemoaned that the assumption that everyone was an English first language speaker, disregarded those not so proficient in the language of teaching and learning. The pre-service teachers pointed out that they would not want their own learners to experience that hence would use code switching where necessary when teaching. Still on the assessment tasks the pre-service teachers indicated that the nature of the feedback they received from this module was not satisfactory for some of the assessments. They indicated that the comments were too blunt and did not give meaningful recommendations for one to improve on their performance. In fact, they bemoaned the negativity they perceived was characteristic of the comments they received in their assessments, a situation which they indicated as demotivating.

Because the pre-service teachers came from different socioeconomic backgrounds with others coming from disadvantaged homes, they reflected on how they struggled to access online teaching and learning materials and online lectures held synchronously. They indicated that the online lectures used up a lot of data via the Blackboard management learning system particularly the blackboard collaborate tool. Whilst they appreciated the lecture slides and lecture recordings made available after every session on the learning management system, they wished the university or government could have subsidised substantially on data for internet connection. They also felt more could be done in the module to enhance training on how to use technological tools in the future.

\section{Discussion}

In the current study the educators of the Life Sciences Methodology module allowed the recipients of their teaching (pre-service teachers) to critically reflect on how they were taught. In this way, the teacher educators had an opportunity to think about their own teaching which Schön (1987) 
referred to as reflection on action. This was meant to inculcate in pre-service teachers the culture of critically reflecting on ones' teaching. This was evident in the findings where pre-service teachers made a realisation of the importance of contextualisation of learning, the role of prior knowledge, consideration of learners' sociocultural backgrounds, their learning styles and preferences, which they (pre-service) resolved to use in their own classrooms. The pre-service teachers appreciated the knowledge and skills they learned about the contextualisation of learning and the use of constructivist teaching strategies. These are competencies which Liu (2015) pointed out as important in analysing and adapting the teaching and learning environment for learners. The pre-service teachers critically reflected on the manner in which they were taught and like what Watson and Kenny (2014) indicated, it is hoped that this improved their pedagogical knowledge and skills for their future classrooms.

When examining the findings from pre-service teachers' critical reflections, the teacher educators of the Module Methodology and Practicum for Life Sciences, may draw a lot of pedagogical and content knowledge aspects for the improvement of the module. The findings show the need to emphasise on the integration of context in their teaching.

\section{Conclusion and recommendations}

Whilst pre-service teachers indicated the relevant knowledge and important pedagogical practices and skills learned in the module, they also brought out aspects which could be done differently in future methodology classes. Within their reflections the integration of subject matter knowledge (Life Sciences content) they learned in the Faculty of Science and the knowledge and skills of how to teach that content to their high school learners stood out. They pointed out the need to identify and select teaching and learning approaches suitable for each Life Sciences topic; the need to contextualise their teaching whilst taking into cognisance the diverse groups of learners found in the classrooms; and the utilisation of ICT affordances considering that online/remote teaching and learning has taken centre stage due to COVID-19 pandemic.

Aspects on the improvement of the module included the need to give clear instructions on assessments; providing meaningful and constructive feedback on assessments; and the need for concerted effort in developing students' ICT skills when teaching Life Sciences. The study informs many preservice teacher development programmes on the need for continuous critical reflection on both the providers and the recipients. In this way, both sides take responsibility for their practices and strive to do better.

\section{References}

Bowen, G. (2009). Document analysis as a qualitative research method. Qualitative Research Journal, 9(2), 27-40.

Creswell, J.W. (2014). Research design. Qualitative, quantitative, \& mixed methods approach (4th edition). Los Angeles: Sage Publications.

Kayapinar, U. (2018). Reflection in teacher development. In V. Mahlangu (Ed.) Reimagining new approaches in teacher professional development pp.776. https://doi.org/10.5772/intechopen.78257

Krumm, P. \& Kimmie, R. (2013). South African Journal of Science, 109(7-8),

Liu, K. (2015). Critical reflection as a framework for transformative learning in teacher education. Educational Review, 67(2), 135-157. http://dx.doi.org/10.1080/00131911.2013.839546

Maor, D. (2003). The Teacher's Role in Developing Interaction and Reflection in an Online Learning Community. Education Media International, 40 (1/2), 127-135. http://doi.org/10.1080/ 0952398032000092170

Moon, J. A. (2004). A handbook of reflective and experiential learning: Theory and practice. London: Routledge Falmer.

Šarić, M. \& Šteh, B. (2017). Critical reflection in the professional development of teachers: Challenges and possibilities much attention. Center for Educational Policy Studies Journal, 7(3), 67-85.

Schön, D. A. (1987). Educating the reflective practitioner. San Francisco, CA: Jossey Bass.

Van Eekelen, I. M., Vermunt, J. D. \& Boshuizen, H. P. A. (2006). Exploring teachers' will to learn. Teachers and Teaching Education, 22(4), 408-423.

Watson, G.P.L. \& Kenny, N. (2014). Teaching critical reflection to graduate students. Collected essays on learning and teaching, 1, 56-61.

Zeichner, K. (2006). Reflections of a university-based teacher educator on the future of college- and university-based teacher education. Journal of Teacher Education 57 (3), 326-340.

Zeichner, K. M. \& Liston, D. (1996). Reflective teaching: An introduction. Englewood Cliffs, NJ: Lawrence Erlbaum Associates Publishers. 